\title{
Penerapan Pendidikan Kesehatan Diet Dengan Kepatuhan Pasien Diabetes Milletus Dilihat Dari 3 J
}

\author{
Yanuar Noer Romadhoni ${ }^{\mathbf{*}}$, Sugiharto ${ }^{2}$ \\ ${ }^{1,2}$ Program Studi Diploma Tiga Keperawatan, Universitas Muhammadiyah Pekajangan Pekalongan, \\ Indonesia \\ *email: fikes@umpp.ac.id
}

\begin{abstract}
Diabetes mellitus control can be in the form of insulin injection, diet, exercise, and medication. Health education can also be provide to improve the knowledge and skills of people with diabetes in controlling their blood sugar. This study aims to find out how the level of knowledge and level of adherence to the diet carried out by DM sufferers is seen from the 3] (schedule, amount, and type of food). The design used in this study was a case study on 2 patients with type 2 diabetes mellitus. The instrument of this research was a questionnaire on the level of adherence to the 3J diet, a questionnaire on the level of adherence. The patient's knowledge before and after the intervention were compared. Their dietary adherence after the intervention were also observed. The results obtained before the intervention the knowledge value of the two respondents were 60 and 53 . After the intervention, the knowledge level of the two respondents became 80 and the average results of the adherence level observation of the two respondents were 86 and 84 . Based on the observation data, the result of the level of dietary compliance in both clients considered complaint with the diet program. It can be concluded that health education about the 3] diet can increase the level of knowledge and dietary compliance in people with diabetes mellitus. This result can be used as a consideration for the health workers to recommend and educate DM patiens and their families to carry out implement an agreed diet program such as the 3 J diet program.
\end{abstract}

Keywords: Diabetes melltus, Diet, Compliance, Health education

\begin{abstract}
Abstrak
Pengendalian diabetes mellitus dapat berupa injeksi insulin, pengaturan diet, olahraga dan obatobatan. Untuk meningkatkan pengetahuan dan keterampilan diabetisi dalam pengendalian gula darah dapat dilakukan pemberian pendidikan kesehatan. Penelitian ini bertujuan untuk mengetahui bagaimana tingkat pengetahuan dan tingkat kepatuhan akan diet yang dijalankan oleh penderita DM dilihat dari $3 \mathrm{~J}$ (jadwal, jumlah dan jenis makanan). Desain karya tulis ilmiah ini berupa studi kasus pada 2 penderita diabetes mellitus tipe 2. Instrument penelitian ini berupa kuesioner tingkat kepatuhan diet 3], kuesioner tingkat pengetahuan tentang diet diabetes mellitus dan lembar observasi tingkat kepatuhan. Cara mengevaluasi dengan membandingkan nilai pengetahuan sebelum dan sesudah intervensi dan observasi nilai kepatuhan diet sesudah intervensi. Hasil yang didapat sebelum dilakukan intervensi nilai pengetahuan kedua responden adalah 60 dan 53. Setelah dilakukan intervensi nilai tingkat pengetahuan kedua responden menjadi 80 dan hasil observasi tingkat kepatuhan kedua responden rata-rata 86 dan 84 . Berdasarkan data observasi didapatkan hasil tingkat kepatuhan diet pada kedua klien dianggap patuh terhadap program diet yang dilakukan. Kesimpulannya adalah pendidikan kesehatan tentang diet 3j dapat meningkatkan tingkat pengetahuan dan kepatuhan diet pada penderita diabetes mellitus. Saran bagi tenaga kesehatan hendaknya menganjurkan dan mengedukasi penderita DM dan keluarganya untuk melakukan dan melaksanakan program diet yang sudah disepakati seperti program diet 3].
\end{abstract}

Kata kunci: diabetes mellitus, diet, kepatuhan, pendidikan kesehatan

\section{Pendahuluan}

Diabetes mellitus atau biasa disebut dengan kecing manis, merupakan suatu penyakit yang ditandai dengan meningkatnya kadar gula dalam darah melewati batas normal (hiperglikemi), yang disebabkan oleh ketidak mampuan kerja dari hormon insulin untuk mengontrolnya. Menurut IDF (International Diabetes Federation) [8]diabetes merupakan penyakit dimana organ pancreas sudah tidak bisa memproduksi hormon insulin yang berguna untuk mengontrol gula dalam darah, atau tubuh sudah tidak bisa lagi 


\section{Prosiding Seminar Nasional Kesehatan 2021 Lembaga Penelitian dan Pengabdian Masyarakat Universitas Muhammadiyah Pekajangan Pekalongan}

memanfaatkan insulin yang diproduksi dengan baik. Menurut Sutanto [11] Diabetes Mellitus diklasifikasikan menjadi tiga tipe utama, yaitu Diabetes tipe 1, Diabetes tipe 2, dan Diabetes Gestasional.Diabetes yang disebutkan terakhir bersifat incidental, karena berhubungan dengan dengan kondisi kehamilan. Menurut WHO pada tahun 1997 dalam Porth [3] diabetes dibagi menjadi empat jenis, antara lain diabetes tipe 1, diabetes tipe 2, diabetes tipe lain serta diabetes kehamilan atau gestasional.

Berdasarkan prevalensi IDF [6], [7] Atlas pada tahun 2019 penderita diabetes mellitus didunia sebesar 8,3 \% dan kemungkinan akan meningkat ditahun 2030 menjadi 9,2\%. Di Indonesia sebesar 10,7 juta penduduk menderita diabetes mellitus. Indonesia berada diperingkat ke 7 di dunia setelah China, India, Amerika Serikat, Pakistan, Brazil dan Mexiko dan peringkat ke 3 di Asia Tenggara setelah China dan India. Pengendalian DM dapat berupa injeksi insulin, pengaturan diet, olahraga dan obat alternatif. Berdasarkan Riskesdas Jateng [9], untuk wilayah kabupaten Pemalang jenis pengendalian DM berdasarkan diagnosis dokter di Indonesia didapatkan hasil 82,65\% pengaturan diet, $60,91 \%$ olahraga, $22,41 \%$ pengobatan herbal, sedangkan penderita DM yang tidak memeriksakan kadar gula darahnya mencapai 90,96\%, kemudian tingkat kepatuhan minum/suntik obat antidiabetes sesuai petunjuk dokter $98,66 \%$ dan tidak sesuai petunjuk dokter $1.34 \%$. Kasus DM yang tidak diobati di Jawa Tengah mencapai 8,75\%, sedangkan untuk wilayah Kabupaten Pemalang terdapat 5,34\% kasus DM yang tidak diobati. Perawat sebagai penatalaksaanaan DM dapat memberikan pendidikan kesehatan kepada pasien secara berkesinambungan. Salah satunya adalah pengaturan program diet. Dengan program diet yang sudah ditetapkan dapat mengendalikan serta mengubah perilaku makan mereka [1].

Kepatuhan penderita DM akan diet memiliki pengaruh yang sangat penting dalam mengontrol kadar gula dalam darah. Kepatuhan ini dapat menjadi hal penting untuk mengembangkan kebiasaan mengontrol asupan makan dan minuman bagi si penderita dalam mengikuti jadwal diet yang dilakukan. Penderita DM yang tidak patuh terhadap jadwal diet yang sudah dilakukan dapat mengakibatkan resiko kenaikan kadar gula dalam darah yang tidak terkontrol. Menurut Tjokoprawiro [12] menyebutkan bahwa diet tepat jumlah, jadwal dan jenis merupakan prinsip pada diet DM. Dengan menggunakan prinsip 3 J ini dapat memudahkan penderita DM untuk mengontrol diet yang dilakukan. Untuk menerapkan prinsip $3 \mathrm{~J}$ ini maka penderita DM sebelumnya harus diberi pendidikan kesehatan terlebih dahulu agar penderita memahami sangat betul tentang program diet 3 $\mathrm{J}$ ini dan dapat menjalankan dietnya dengan teratur

Berdasarkan dari uraian latar belakang ini, penulis tertarik untuk melakukan penelitian tentang "Pendidikan kesehatan Diet dengan Kepatuhan Pasien Diabetes Mellitus dilihat dari 3J", untuk meningkatkan tingkat kepatuhan diet pada penderita DM dilihat dari 3 J yaitu Jumlah makan, jadwal makan dan jenis makan untuk mengontrol kadar gula dalam darah.

\section{Metode}

Penelitian ini menggunakan desain atau rancangan berupa studi kasus. Study kasus adalah mengembangkan analisis yang mendalam terhadap suatu kasus, aktivitas atau proses individu atau kelompok dan mengobservasi serta mengumpulkan informasi secara lengkap dengan prosedur pengumpulan data yang sudah ditentukan [10]. Studi kasus ini dilakukan di desa Cibelok Kecamatan Taman Kabupaten Pemalang selama 5 hari. Subjek studi kasus ini adalah dua orang klien yang memenuhi kriteria inklusi responden yaitu, pria atau wanita usia kerja (20 tahun-65 tahun) dan memiliki riwayat penyakit DM tipe 2, Membutuhkan terapi diet, belum memahami tentang diet 3J diabetes mellitus. Sebelum melakukan pendidikan kesehatan, klien akan diberikan kuesioner untuk mengetahui tingkat pengetahuan responden akan diet yang dijalankan. Kemudian setelah dilakukan pendidikan kesehatan responden akan diberikan kuesioner untuk mengetahui apakah ada peningkatan pengetahuan. Kemudian klien rutin diberikan kuesioner Tingkat Kepatuhan Diet setiap hari untuk memantau apakah responden melaksakan dietnya atau tidak. 


\section{Prosiding Seminar Nasional Kesehatan 2021 \\ Lembaga Penelitian dan Pengabdian Masyarakat Universitas Muhammadiyah Pekajangan Pekalongan}

\section{Hasil dan Pembahasan Hasil}

Karakteristik dari kedua klien pada penelitian ini adalan klien 1 berusia 38 tahun jenis kelamin laki-laki dan sudah menderita diabetes tipe 2 selama kurang lebih 4 tahun, pada klien 2 berusia 54 tahun jenis kelamin perempuan dan sudah menderita diabetes tipe 2 selama kurang lebih 4 tahun. Kedua klien memiliki persamaan yaitu sama-sama memiliki diabetes mellitus tipe 2, dan perbedaan pada jenis kelamin dan umur.

klien sebelum dan sesudah dilakukan pendidikan kesehatan diberikan kuesioner pengetahuan diet DM. Hasil yang didapat dari kuesioner yang diberikan sebelum pendidikan kesehatan adalah klien 1 mampu menjawab 60 dari total benar dan klien 2 mampu menjawab 53 dari total benar. Kemudian setelah dilakukan pendidikan kesehatan, klien 1 mampu menjawab 80 dari total benar dan klien 2 mampu menjawab 80 dari total benar. Dari analisa yang dilakukan kedua klien mengalami peningkatan pengetahuan tentang diet DM.

Observasi tingkat kepatuhan pada kedua klien selama 5 hari setelah dilakukan pendidikan kesehatan tentang diet DM 3J didapatkan hasil pada klien 1 dengan rata-rata $86 \%$ dan klien 2 dengan rata-rata kepatuhan 83\%. Hasil ini membuktikan bahwa kedua klien patuh dalam melakukan diet DM 3J.

\section{Pembahasan}

Analisa karakterisitk demografi klien pada penulisan karya tulis ilmiah ini ditinjau berdasarkan karakteristik demografi memperlihatkan bahwa klien 1 dan 2 memiliki persamaan tipe diabetes mellitus yang diderita, namun ditemukan perbedaan usia dan jenis kelamin, pada klien 1 laki-laki berusia 38 tahun dan klien 2 perempuan berusia 54 tahun.

Setelah dilakukan pendidikan kesehatan pada kedua klien, telah memahami materi yang dijelaskan seperti pendidikan kesehatan tentang diet $3 \mathrm{~J}$ (Jumlah,Jadwal dan Jenis) pada penderita diabetes mellitus. Pendidikan kesehatan tentang diet $3 \mathrm{~J}$ (Jumlah, jadwal dan Jenis) pada Penderita Diabetes Mellitus khususnya metode penyajian makanan meliputi menentukan jumlah makanan yang diperlukan, menentukan jadwal makan, dan menentukan jenis makanan. Dengan tujuan klien mampu memahami dan melaksanakan diet 3J yang dianjurkan serta mampu patuh melaksanakan diet yang sudah diberikan. Rasional dari tindakan keperawatan yang diberikan yaitu untuk memberikan gambaran tentang diet 3J bagi penderita diabetes mellitus dengan mengajarkan cara yang tepat meliputi cara menyajikan makanan, cara menentukan jumlah, jadwal dan jenis makanan dan minuman. Sesuai pernyataan Induniasih dan Ratna [5] pendidikan kesehatan merupakan sebuah cara atau upaya untuk memberikan dan meningkatkan informasi kepada individu, komunitas atau masyarakat terkait dengan kesehatan. Kemudian diperoleh hasil implementasi adanya perubahan tingkat pengetahuan dan perubahan perilaku kedua klien antara sebelum dan sesudah dilakukan Asuhan Keperawatan Pasien dengan Diabetes Mellitus. Hal ini dilakukan agar timbulnya proses adaptasi perilaku menurut Notoatmojo [4] yaitu sebelum seseorang mengadopsi perilaku baru, di dalam diri orang tersebut terjadi proses yang berurutan, yaitu awareness (kesadaran), interest (ketertarikan), evaluation (menimbang nimbang), trial (mencoba), dan adoption (berperilaku baru).

Secara keseluruhan tingkat pengetahuan dan perubahan perilaku kedua klien, antara klien 1 dan klien 2 menunjukkan adanya persamaan yang didapat yaitu adanya peningkatan pengetahuan yang ditunjukkan dengan data subyektif yang didapat yaitu klien mengatakan mengerti tentang Diet 3]. Sedangkan data obyektif yang didapat pada klien : klien dapat menjelaskan kembali tentang Diet 3j pada penderita diabetes mellitus, klien dapat menyajikan makanan sesuai dengan diet 3j secara mandiri, adanya peningkatan persentase kuisioner pengetahuan klien 1 dari 60 menjadi 80 jawaban benar dan klien 2 dari 53 menjadi 80 jawaban benar dan didapat hasil tingkat kepatuhan dalam melaksanakan diet 3] yaitu klien 1 dengan rata-rata tingkat keaptuhan $86 \%$ dan klien 2 


\section{Prosiding Seminar Nasional Kesehatan 2021 Lembaga Penelitian dan Pengabdian Masyarakat Universitas Muhammadiyah Pekajangan Pekalongan}

dengan tingkat rata-rata kepatuhan $83 \%$, hal ini menunjukkan bahwa kedua klien patuh dalam melaksanakan dietnya. Hal ini sejalan dengan penelitian yang dilakukan oleh Bistara dan Ainiyah [2] tingkat pengetahuan berhubungan dengan kepatuhan diet diabetes mellitus, apabila penderita Dm memiliki pengetahuan yang baik maka akan mempengaruhi kepatuhan diet DM.

\section{Kesimpulan}

Hasil dari Asuhan Keperawatan yang dilakukan selama 5 kali kunjungan pada kedua klien dengan fokus studi defisit pengetahuan tentang diet 3J pada kedua klien diperoleh hasil adanya perubahan tingkat pengetahuan dan perilaku kepatuhan terhadap diet yang dilakukan. Hal ini dibuktikan dengan adanya peningkatan persentase pada kuesioner pengetahuan yaitu pada klien 1 dari $60 \%$ menjadi $80 \%$ jawaban benar dan pada klien 2 yaitu dari $53 \%$ menjadi $80 \%$ jawaban benar. Kemudian tingkat kepatuhan diet klien selama 5 hari yang dipantau dengan kuesioner tingkat kepatuhan diet didapatkan hasil rata-rata tingkat kepatuhan pada klien 1 yaitu 86\% dan rata - rata tingkat kepatuhan klien 2 yaitu 84\%, dimana kedua klien dianggap patuh dalam melaksanakan dietnya.

\section{Referensi}

[1] Arfina, A.(2019). Pengauh Edukasi Pengaturan Diet Terhadap Perilaku Pengolahan Diet Pada Penderita Diabetes Mellitus Dikelurahan Agrowisata Kecamatan Rumbai Kota Pekan Baru. Indonesian Trust Health Journal. ISSN: 2620-5564, Vol 2, No-2 November. 2019.

[2] Bistara, D.N dan Ainiyah, N. (2018). Hubungan pengetahuan dengan kepatuhan diet pada penderita diabetes mellitus di Posyandu Lansia Cempaka Kelurahan Tembok Dukuh Kecamatan Bubutan Surabaya. Jurnal IImiah Kesehatan, 13 (1), 51-57. doi: 10.33086/jhs.v11i.117

[3] Damayanti, S. (2018).Diabetes Mellitus dan Penatalaksanaan Keperawatan. Yogyakarta: Nuha Medika

[4] Dewi dan Wawan (2011). Pengetahuan Sikap dan Perilaku Manusia. Yogyakarta : Nuha Medika

[5] Induniasih dan Ratna, W. (2018). PROMOSI KESEHATAH. Yogyakarta: PUSTAKA BARU PRESS

[6] International Diabetes Federation.(2019). IDF Diabetes Atlas 2019: Demographic and Geographic Outline. Diambil dari https://diabetesatlas.org/en/sections/demographic-and-geographic-outline.html

[7] International Diabetes Federation.(2019). IDF Diabetes Atlas 2019: regional Factsheet. Diambil dari https://diabetesatlas.org/en/resources/

[8] International Diabetes Federation.(2020). IDF About Diabetes : What is Diabetes. Diambil dari https://idf.org/aboutdiabetes/what-is-diabetes.html

[9] Kementrian Kesehatan Republik Indonesia.(2018). Riset Kesehatan Daerah Provinsi Jawa Tengah 2018. Jakarta: Lembaga Penerbit Badan Penelitian dan Pengembangan Kesehatan

[10] Khairani, A.I., \& Manurung, W.R.A. (2019). Metodologi Penelitian Kualitatif Case Study. Jakarta: TIM, 2019 
Prosiding Seminar Nasional Kesehatan 2021

Lembaga Penelitian dan Pengabdian Masyarakat

Universitas Muhammadiyah Pekajangan Pekalongan

[11] Sutanto, T. (2013). Diabetes: Deteksi, Pencegahan, Pengobatan. Yogyakarta: BUKU PINTAR

[12] Yusran, H. (2018). Pelatihan Pengelolaan Makan dengan 3] Pada Penderita DM Beserta Keluarganya Di Kecamatan Simbang Kabupaten Maros. Jurnal Dedikasi Masyarakat, 2(1), 11-1. ISSN. 2598-7984 